\title{
Achieving and Maintaining Cleanliness in NIF Amplifiers
}

\author{
I. F. Stowers \\ J. A. Horvath \\ J. A. Menapace \\ A. K. Burnham \\ S. A. Letts
}

This paper was prepared for submittal to the Third Annual International Conference on Solid State Lasers for Application (SSLA)

to Inertial Confinement Fusion (ICF) Monterey, California

June 7-12, 1998

July 28, 1998

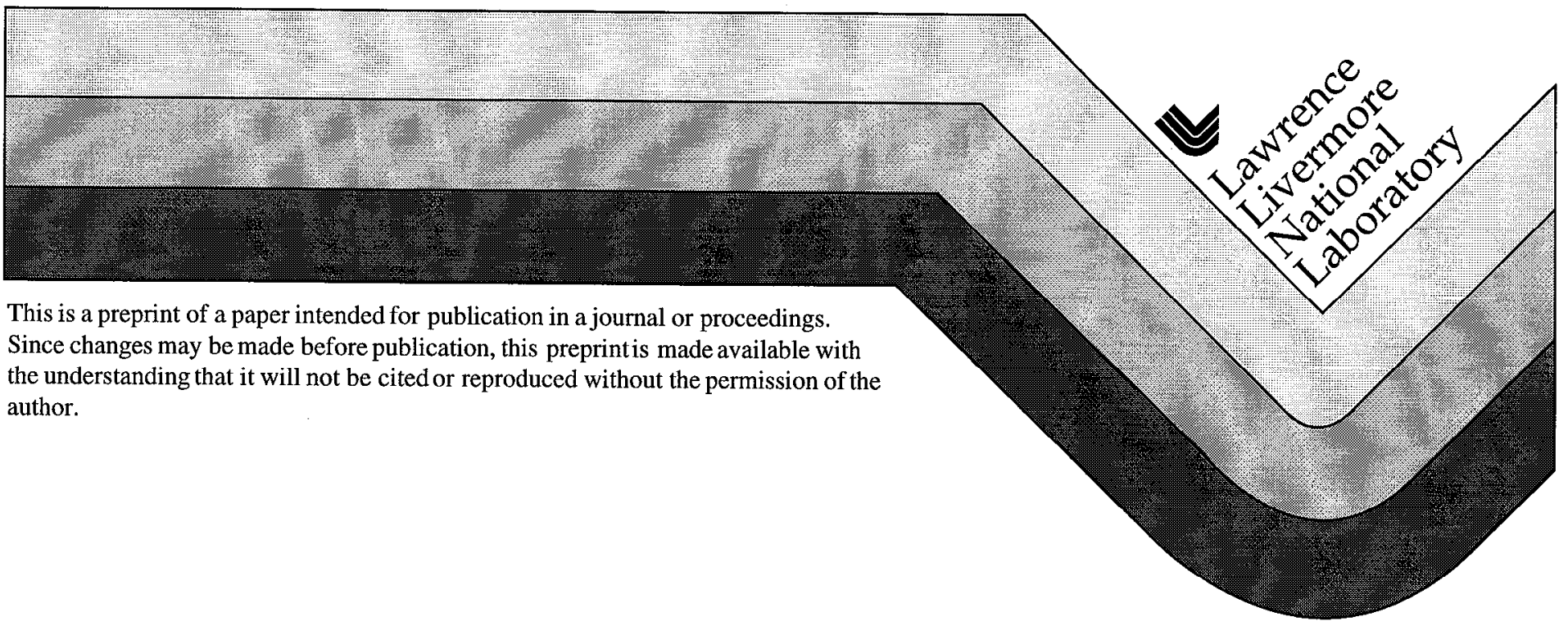




\section{DISCLAIMER}

This document was prepared as an account of work sponsored by an agency of the United States Government. Neither the United States Government nor the University of California nor any of their employees, makes any warranty, express or implied, or assumes any legal liability or responsibility for the accuracy, completeness, or usefulness of any information, apparatus, product, or process disclosed, or represents that its use would not infringe privately owned rights. Reference herein to any specific commercial product, process, or service by trade name, trademark, manufacturer, or otherwise, does not necessarily constitute or imply its endorsement, recommendation, or favoring by the United States Government or the University of California. The views and opinions of authors expressed herein do not necessarily state or reflect those of the United States Government or the University of California, and shall not be used for advertising or product endorsement purposes. 


\title{
Achieving and Maintaining Cleanliness in NIF Amplifiers
}

\author{
I.F. Stowers, J.A. Horvath, J.A. Menapace, A.K. Burnham, and S.A. Letts \\ Lawrence Livermore National Laboratory \\ PO Box 808, L-487, Livermore, CA 94550
}

\begin{abstract}
Cleanliness measurements made on AMPLAB prototype National Ignition Facility (NIF) lascr amplifiers during assembly, cassette transfer, and amplifier operation are summarized. These measurements include particle counts from surface cleanliness assessments using filter swipe techniques and from airborne particle monitoring. Results are compared with similar measurements made on the Beamlet and Nova lasers and in flashlamp test fixtures. Observations of Class 100,000 aerosols after flashlamp firings are discussed. Comparisons are made between typical damage densities on laser amplifier optics from Novette, NOVA, Beamlet, and AMPLAB.
\end{abstract}

Kcywords: Optical Cleanliness, Glass Crazing, MIL STD 1246C, Damage Maps, Aerosols, Flashlamp Induced Damage

\section{BACKGROUND}

When completed, the NIF will be the largest face-pumped solid-state laser ever constructed. Face-pumped lasers are particularly sensitive to extrinsic damage because the face of the lasing media (slabs or disks) is within the flashlamp cavity and exposed to the full fluence of the flashlamp illumination. The flashlamp fluence in NIF will be $10 \mathrm{~J} / \mathrm{cm}^{2}$ with a $360 \mu \mathrm{s}$ pulse. In addition, the slab faces will be exposed to a maximum fluence (outside slab) of approximately $18 \mathrm{~J} / \mathrm{cm}^{2}$ with a $5-\mathrm{ns}$ $1.053-\mu \mathrm{m}$ pulse. Recent work, described briefly here, indicates that flashlamp illumination is the main cause of slab damage when contaminant particles are allowed to reach the slab surface. Here, the temperature rise of surface contaminants, in response to flashlamp illumination, is sufficient to melt or decompose most contaminant particles. The local thermal gradient created on the slab surface, in conjunction with the low thermal shock parameter of the lasing media, combine to craze the slab surface.

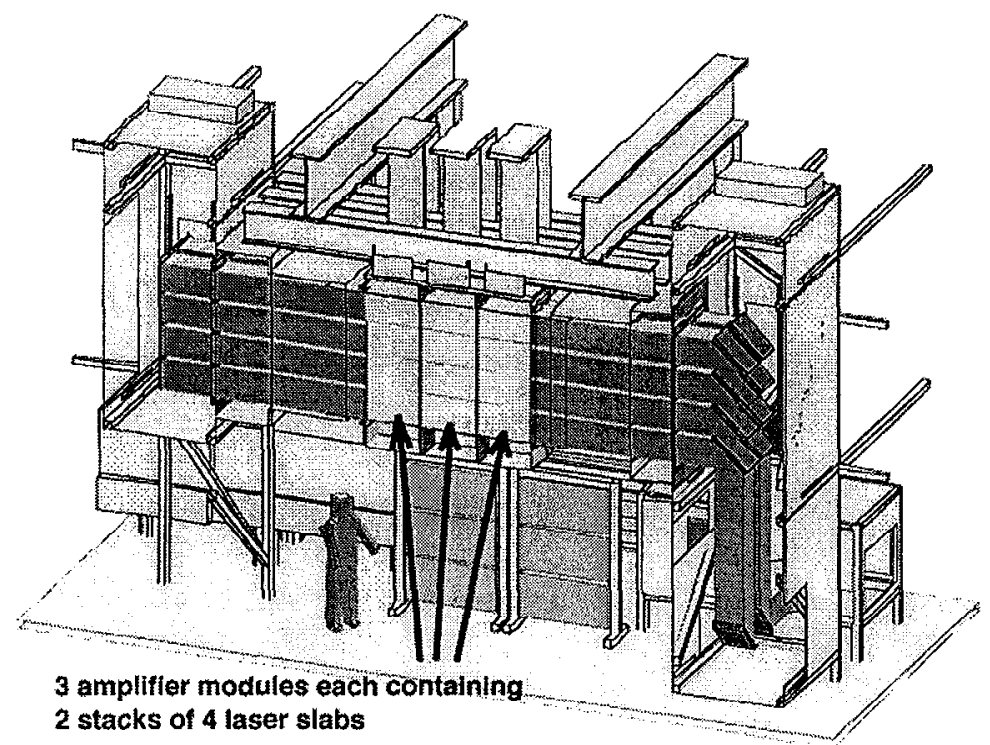

Figure 1: Schematic of the AMPLAB facility at LLNL. The three amplifiers each contain two slab cassettes each containing a stack of four slabs and flashlamp casscttes. The flashlamp cassettes contain six (sidc) or eight (central shared) flashlamps.

LLNL has constructed an Amplifier Laboratory (AMPLAB) to prototype the new Line Replaceable Unit (LRU) amplifier design and to extract information concerning its optical, thermal, and cleanliness characteristics as related to the NIF. The AMPLAB contains three amplifier modules each containing two adjacent stacks of four laser slabs. The AMPLAB facility includes a clean amplifier transport vehicle and a Class 100 cleanroom within which the four slab cassettes are cleaned and assembled. The AMPLAB facility is shown in Figure 1. The NIF amplifier design differs from other solid-statc lasers 
constructed at LLNL in that it utilizes a modular LRU concept in which optical and other electro-mechanical components, more likely to need periodic inspection and/or replacement, are removable in the form of a cassette. In the specific case of slab amplifiers, the permanent housing is called a Frame Asscmbly Unit (FAU) and is a part of the laser system. The amplifier LRU contains only laser slabs and reflectors and is referred to as the amplifier cassette. Additional LRUs contain the flashlamps and blastshields.

\section{CLEANLINESS MEASUREMENTS}

\subsection{System cleanliness requirements}

The NIF Program has established a series of particle cleanliness requirements for its laser systems. The NIF optical surface cleanliness requirements are based on 1) the need to maintain scattered light per surface ${ }^{1}$ below 1 part in $10^{5}$ and 2) to prevent the largest damage site on any slab from exceeding $250-\mu \mathrm{m}$ in diameter ${ }^{2,3,4}$ The requirements also specify that structural surfaces should be maintained at a cleanliness Level no more than 10 times higher than the optical surfaces. These specifications are derived_from previous experience with the reliability of cleanliness measurement methods and available cleaning procedures for both surface types. Particulate cleanliness is reported using MIL STD $1246 C^{5}$, Figure 2, which defines a series of particle size distributions which have been found to be similar to the size distributions generally found on optical and structural surfaces. Level 50 (at the boundary of very low scattering surfaces) has been selected as the optical cleanliness necessary for installed optics and Level 100 has been selected as the cleanliness necessary for installed mechanical components.

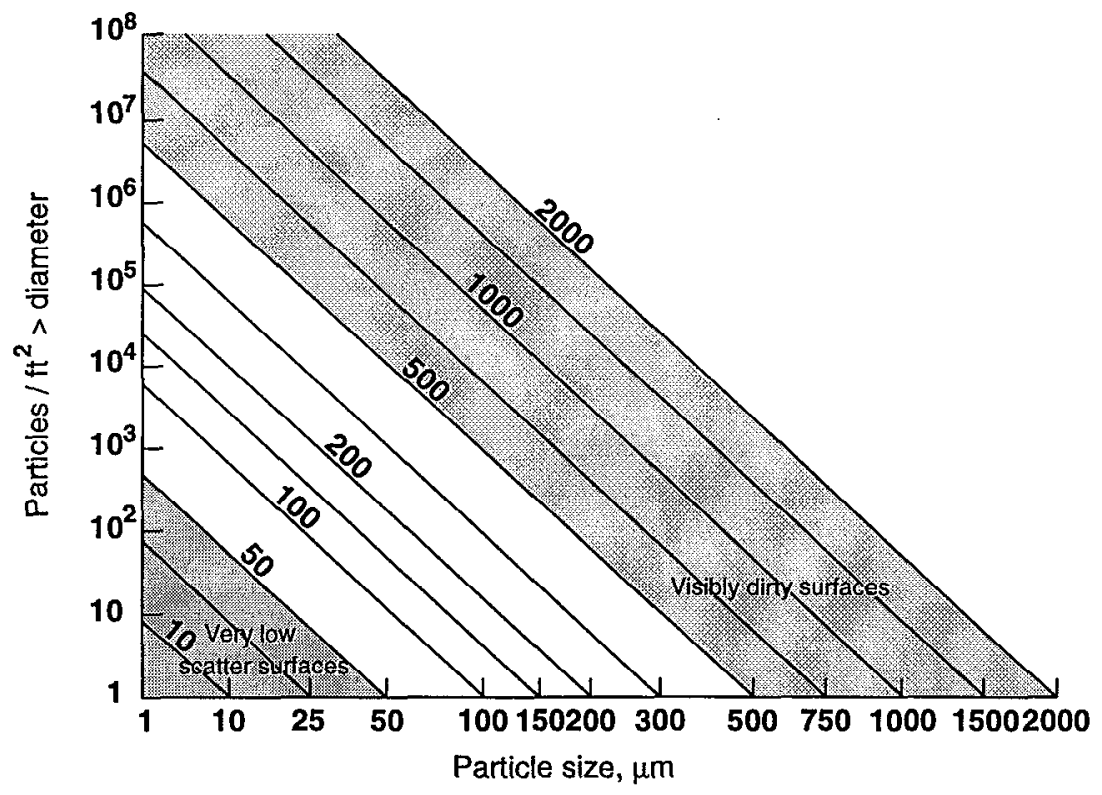

Figure 2: Size distributions for several Military Standard 1246C cleanliness Levels. Level 50 defines a line with no more than 166 particles $/ \mathrm{ft}^{2}$ exceeding $5-\mu \mathrm{m}$ in diameter and no more than 1 particle/ $\mathrm{ft}^{2}$ exceeding $50-\mu \mathrm{m}$. In a similar way, Level 100 represents a cleanliness Level of no more than 1785 particles/ $\mathrm{ft}^{2}$ exceeding $5-\mu \mathrm{m}$ in diameter and no more than 1 particle/ $\mathrm{ft}^{2}$ exceeding $100-\mu \mathrm{m}$.

\subsection{Initial AMPLAB cleanliness}

During construction, the AMPLAB FAU, flashlamp LRU, blastshield LRU, and amplifier LRU components were cleaned by LLNL best-known procedures. ${ }^{6}$ These procedures include hot water/surfactant spraying (Brulin $815 \mathrm{GD}$ ), high pressure (>1,000-psi) distilled water washing, cleanroom bagging (Class 100 nylon and polyethylene bags), and controlled transportation to the AMPLAB facility where they were precision cleaned with either $\mathrm{CO}_{2}$ snow or solvent wiped with absolute ethyl alcohol. Initial cleanliness is validated by wiping the surfaces with an ultra-clean membrane filter (a process called swiping ${ }^{7}$ ). The particles contained on the filter paper surface are subsequently counted with a dark-field microscope at 100x magnification. The quantity of particles greater than $5-\mu \mathrm{m}$ is used to ascertain the Level of cleanliness as described in MIL STD 1246C. 
Table 1 shows the cleanliness Levels measured on several optical and structural surfaces following initial installation in AMPLAB and after several months of routine operation. These measurement indicate that the NIF surface cleanliness goals of Level 50 and Level 100 are being approached but are not routinely being maintained.

Experiments currently underway involve a complete AMPLAB facility disassembly and re-assembly after gross chemical cleaning to remove all electroless nickel surface coatings followed by precision $\mathrm{CO}_{2}$ snow and high pressure water washing. These experiments will determine if the current NIF surface cleanliness requirements can be routinely achieved and maintained. The experiments will also quantify the size distribution of slab damage after short (20 shot) and relatively long (500 shot) flashlamp firing sequences. This information will be used to establish the final NIF cleanliness specifications and to estimate long term NIF slab damage.

Table 1: Cleanliness Level ranges measured at several locations in AMPLAB after the facility was brought on-line. The structural surface cleanliness goals are Level $100 / 2=$ Level 83 immediately after cleaning and Level 100 when installed. Optical surface cleanliness goals are < Level 50 immediately after cleaning and Level 50 when installed.

\begin{tabular}{|l|c|c|}
\hline \multicolumn{1}{|c|}{ Location } & $\begin{array}{c}\text { Cleanliness } \\
\text { Level }\end{array}$ & $\begin{array}{c}\text { Particles/ft } \mathbf{~}^{\mathbf{2}} \\
\mathbf{5 - \mu \mathbf { m } \text { diameter }}\end{array}$ \\
\hline Structural surface within body of amplifier & $82-137$ & $869-5,960$ \\
\hline Floor of cassette & $88-141$ & $1,119-6,900$ \\
\hline Slab surfaces & $44-77$ & $112-697$ \\
\hline
\end{tabular}

\subsection{Beamlet laser cleanliness}

In October 1997 a turning mirror box and several amplifier modules on Beamlet were examined to determine surface cleanliness Levels after approximately four years of routine operation. The areas opened for examination were protected from airborne contamination by placing large vertical flow HEPA filter carts over each area and by utilizing cleanroom personnel protective equipment which included cleanroom jump suits, hoods with face masks, gloves with taped wrists and high cleanroom boots. Three locations were sampled within the southwest mirror box which include 1) horizontal and vertical structural surfaces, 2) beam tube surfaces leading into the mirror box, and 3) mirror surfaces. The surface cleanliness Level on all of these surfaces was typically found to be Level 150 (Table 2).

Table 2: Surface cleanliness Level at various locations inside the Beamlet laser system at LLNL.

\begin{tabular}{|c|c|c|}
\hline \multicolumn{1}{|c|}{ Location } & $\begin{array}{c}\text { Cleanliness } \\
\text { Level }\end{array}$ & $\begin{array}{c}\text { Particles/ft } \\
\mathbf{2} \\
\mathbf{5 - \mu m} \text { diameter }\end{array}$ \\
\hline Beamlet mirror box & & \\
\hline Beam tube & 143 & 7,155 \\
\hline M2 cavity mirror: front surface & 153 & 9,253 \\
\hline M3 mirror: upward facing surface & $\mathbf{1 4 6}$ & 7,707 \\
\hline Cavity amplifiers & & 30,156 \\
\hline C1 bottom reflector & 203 & 10,222 \\
\hline C2 lower disk surface & 157 & \\
\hline Output amplifiers B4-B5 & & 8,293 \\
\hline B4 disk surface & 149 & 157,703 \\
\hline $\begin{array}{l}\text { B4 reflector: top of top reflector - } \\
\text { visible dust on surfaces }\end{array}$ & 295 & 5,612 \\
\hline B5 disk surface & 135 & 21,174 \\
\hline Beam tube & 187 & \\
\hline
\end{tabular}

Similar cleanliness measurements were taken after opening two amplifier modules. Swipes were taken on horizontal and vertical structural surfaces and on optical slab surfaces. Results of these cleanliness mcasurements indicate that both the structural surfaces and the optical surfaces were typically at Level 170 (Table 2).

These observations lead to the following conclusions:

- The structural surface cleanliness of Beamlet was considerably lower (cleaner) than Level 150-170 when it was initially constructed in 1993 based on cleanliness measurements made of the effluents of the washing fluids. These effluent 
samples indicate that all surfaces were cleaner than Level 100 when the parts were allowed to leave the high-pressure water-cleaning station.

- The mirror box has become significantly dirtier during the four-year operational lifetime of Beamlet. An increase from Level 100 to Level 150 represents an increase of $380 \%$ in cavity contamination level.

- Amplifier surfaces have degraded (become dirtier) during the Beamlet lifetime and the amplifier optical surfaces (which were initially cleaner than the structural surfaces), have degraded to a cleanliness Level nearly identical to that of the structural surfaces. This indicates that some mechanism, such as laser surface cleaning ${ }^{8}$, vibrational disruption of surface particles, or pyrolysis of elastomers and/or organic materials, has been continuously creating new particles and mobilizing residual cleaning particles inside the laser cavity with subsequent aerodynamic settling onto structural and optical surfaces.

- This flux of airborne particulate contaminants seems to form a cleanliness equilibrium in which the cleaner optical surfaces approach a cleanliness Level nearly equal to that of the dirtier surfaces, at the time of initial assembly. Additionally, a mechanism exists (described in Section 3) that causes chemical degradation of organic and elastomeric materials within the amplifier and causes a carbon aerosol to be created. This aerosol particulate material appears to accumulate within amplifiers and mirror boxes and continually raises the average cleanliness Level.

\subsection{Current AMPLAB cleanliness}

In March 1998, several sections of the AMPLAB facility was carefully recleaned after the occurrence of several cleanlinesscompromising incidents that included flashlamp explosions and dry rubbing of surfaces during cassette insertion and removal. All internal amplifier surfaces (FAU and cassette surfaces) were cleaned by wiping with absolute ethanol moistened cleanroom-wiping cloths. The process was repeated three times and the surface cleanliness was validated using membrane filter paper swipes before and after each wiping operation. The surface cleanliness was found to decrease from Level 215 to Level 140 after the first cleaning, to Level 110 after the second cleaning, and finally to Level 100 after the third and final alcohol wiping operation. This progressive improvement in surface cleanliness is typical of statistically based cleaning processes and represents the inherent inefficiency of hand wiping when applied in ultra-clean environmental situations. The inefficiency can be rationalized as stemming from missing an area during successive cleaning passes or from failure of the wiping cloth to retain the contaminants within the surface fibers and thus, the contaminants are merely redistributed over the surface.

\section{OBSERVATIONS OF AEROSOLS IN AMPLIFIERS}

Airborne particle cleanliness is of as much concern as surface contamination because any mechanism which is able to mobilize particles from a solid surface (shock induced release due to short pulse laser illumination, particle melting, or pyrolysis of low decomposition temperature materials) provides a transport mechanism by which particles could reach an optical surface and thereby result in surface damage. To monitor airborne particles, a multi-port aerosol particle detector ${ }^{9}$ was attached to eight locations on AMPLAB to measure particle size distributions immediately before and after a flashlamp firing. Aerosol concentrations as high as $8 \times 10^{5}$ particles $/ \mathrm{ft}^{3} \geq 0.3-\mu \mathrm{m}$ were routinely detected. (Figure 3 ). At first it was felt that the concentration might be the release of surface contaminant particles due to intense flashlamp heating. However, repeated flushing of the slab cavity with a high flow of filtered nitrogen (approximately $600 \mathrm{ft}^{3} / \mathrm{min}$ compared to the normal nitrogen back-fill rate of $8 \mathrm{ft}^{3} / \mathrm{min}$ ) immediately following the flashlamp firing, failed to prevent the aerosol from reappearing on subsequent amplifier firings. These experiments merely reduced the time to achieve a four order of magnitude decrease in airborne particle concentration to 3 minutes.

Several locations on the LLNL Beamlet laser adjacent to slab amplifiers have also been tested for the presence of aerosols. Figure 4 shows a Beamlet aerosol measurement and indicates that a Class 200,000 aerosol is created after each flashlamp firing. Several locations on the NOVA laser and a single measurement on a Phébus ${ }^{10}$ flashlamp cavity indicate that aerosols measuring approximately Class 100,000 are not at all uncommon in laser systems and appear to be ubiquitous despite not having been previously reported. This may stem from the fact that a Class 100,000 aerosol, although easily measured with an aerosol particle counter, is about the same airborne particle concentration as is found in a modern office building or that exists outdoors on a clear day. Both of the aerosols are invisible to the naked eye unless probed with a high intensity spotlight or laser beam. It is of interest, though unexplained at this time, that all of the measured aerosols are created in the vicinity of a flashlamp cavity and that the flashlamp fluence is approximately $10 \mathrm{~J} / \mathrm{cm}^{3}$. Is seems entirely too coincidental that the aerosols all have similar peak concentrations in the presence of nearly identical flashlamp intensity.

\subsection{Chemistry of aerosols}

Sampling of the aerosol with a cascade impact collector ${ }^{11}$ and subsequent examination in a scanning electron microscope revealed that the aerosol was composed primarily of $\approx 0.1-0.2-\mu \mathrm{m}$ carbon particles (soot). These smaller particles readily agglomerate to form larger airborne particle of up to $20-\mu \mathrm{m}$ in size (with an estimated density of $<0.1 \mathrm{~g} / \mathrm{cm}^{3}$ ). Based upon 
our obscrvation that slab damage is 7.8 times the size of the particle that initiated the damage (see Section 5), a single $20-\mu \mathrm{m}$ particle could result in a $150-\mu \mathrm{m}$ diameter damage site.

Due to the observed chemical identity of the aerosols, it is postulated that they originate from the pyrolysis (decomposition) of organic materials used as gaskets and seals within AMPLAB (alternatively, they could be from organic films adsorbed onto the walls of the amplifier). Future experiments on AMPLAB will determine the exact source of these aerosols and the final NIF amplifier design will be modified to change elastomer composition or protect these surfaces so that they are not exposed to direct flashlamp or laser illumination.

\subsection{Dissipation of aerosols}

The aerosol concentration slowly dissipates in AMPLAB and Beamlet and other measured locations due to a combination of dilution (as filtered nitrogen is slowly added to the amplifier cavity) and Stokes' settling of the particles.

The total filtered nitrogen back-fill on AMPLAB is about $4 \mathrm{ft}^{3} / \mathrm{min}$ and the three amplifier modules have a combined volume of approximately $200-\mathrm{ft}^{3}$. This leads to a dilution rate of $2 \% / \mathrm{min}$ and furthermore, this dilution rate is nearly identical to the slope of the aerosol concentration seen in Figure 3. The dilution mechanism was experimentally verified by varying the backfill rate and measuring the dilution rate that followed a flashlamp firing.

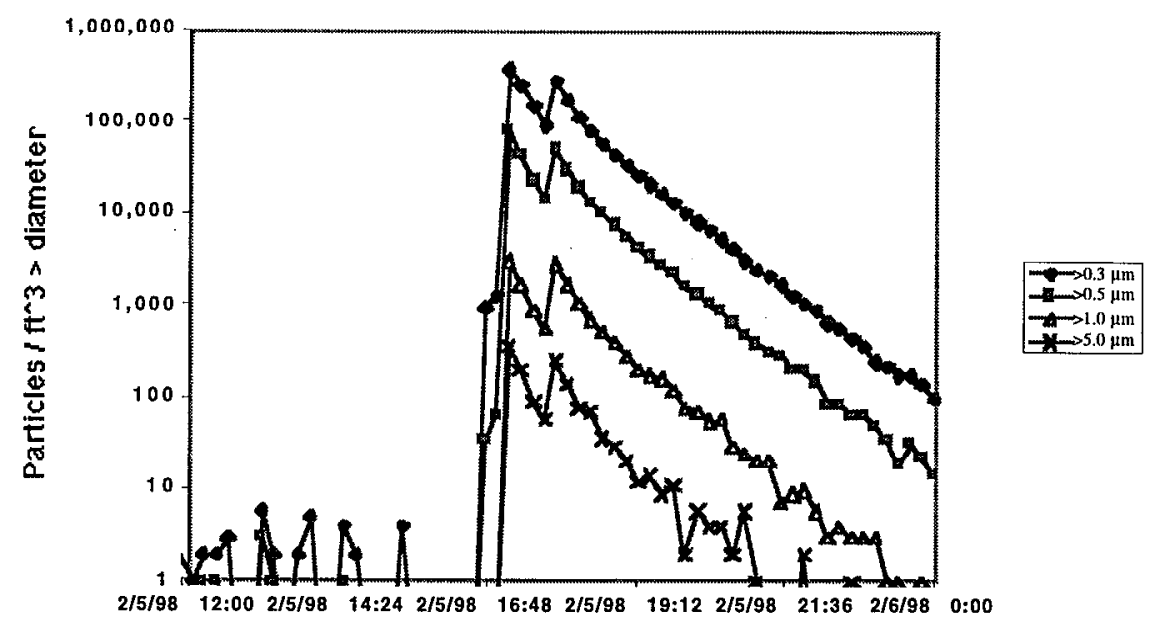

Figure 3 Aerosol size distribution observed in AMPLAB immediately following two flashlamp firings. The concentration represents the total particle count per cubic foot exceeding the aerosol diameter. Aerosol Classes are based on the concentration exceeding $0.5-\mu \mathrm{m}$. This aerosol is therefore referred to as a Class 100,000 aerosol. The decrease in concentration after the flashlamp firing is the result of particle settling and dilution of the nitrogen due to a constant in-flow of clean nitrogen at approximately $4 \mathrm{ft}^{3} / \mathrm{min}$.

The settling rate of $0.5-\mu \mathrm{m}$ particles is highly dependent on particle density and is roughly $0.0015 \mathrm{ft} / \mathrm{min}$ (for a density of $1 \mathrm{~g} / \mathrm{cm}^{3}$ ) or $67 \mathrm{hr}$ for a particle to settle from the top to the bottom of a $6-\mathrm{ft}$ high amplificr. The settling rate of $5-\mu \mathrm{m}$ particles is about $0.15 \mathrm{ft} / \mathrm{min}$ or only 40 minutes to settle the same 6-ft distance. Due to these different settling rates, higher removal rates of larger particles compared to smaller particles should be evident. A careful examination of Figure 3 confirms that the larger size particles show a slightly higher rate of removal from the enclosed system as evidenced by the larger slope of the $\geq 5-\mu \mathrm{m}$ curve compared to that corresponding to the $\geq 0.5-\mu \mathrm{m}$ particles-

\section{DIRECT REMOVAL OF SURFACE PARTICLES BY SHORT PULSE LASER LIGHT}

Experiments are currently being conducted (in collaboration with the University of California at Berkeley and Clarkson University, Potsdam, NY) to study the mobilization of contaminant particles under the influence of short pulse laser light. Table 3 lists several substrate surfaces that were contaminated with low concentrations of small particle contaminants. The contaminants are dry-loaded onto the substrate surfaces that are then photomicrographed in selected areas prior to laser exposure. The areas and the photomicrographs are identified by their respective offsets from the substrate corners as measured using a XY stage on a laboratory microscope. This enables easy relocation of the areas during laser exposure and allows precise photomicrographs to be taken during post laser data reduction and resultant intcrprctation. In most instances, four tiled photomicrographs are taken in each of the areas at 50 or $100 \mathrm{x}$ total magnification. This yields approximately $1 \mathrm{~mm}$-square areas to be analyzed in each area undergoing laser cleaning. The samples are then exposed to 6-ns 1.064- $\mu \mathrm{m}$ laser light pulses. 
After laser exposure, the samples are re-examined and photomicrographed to provide a measure of the onset and efficiency of the laser induced particle mobilization. Surface contaminant identification software developed at LLNL is used to provide contaminant mobilization fluence values and removal efficiencies.

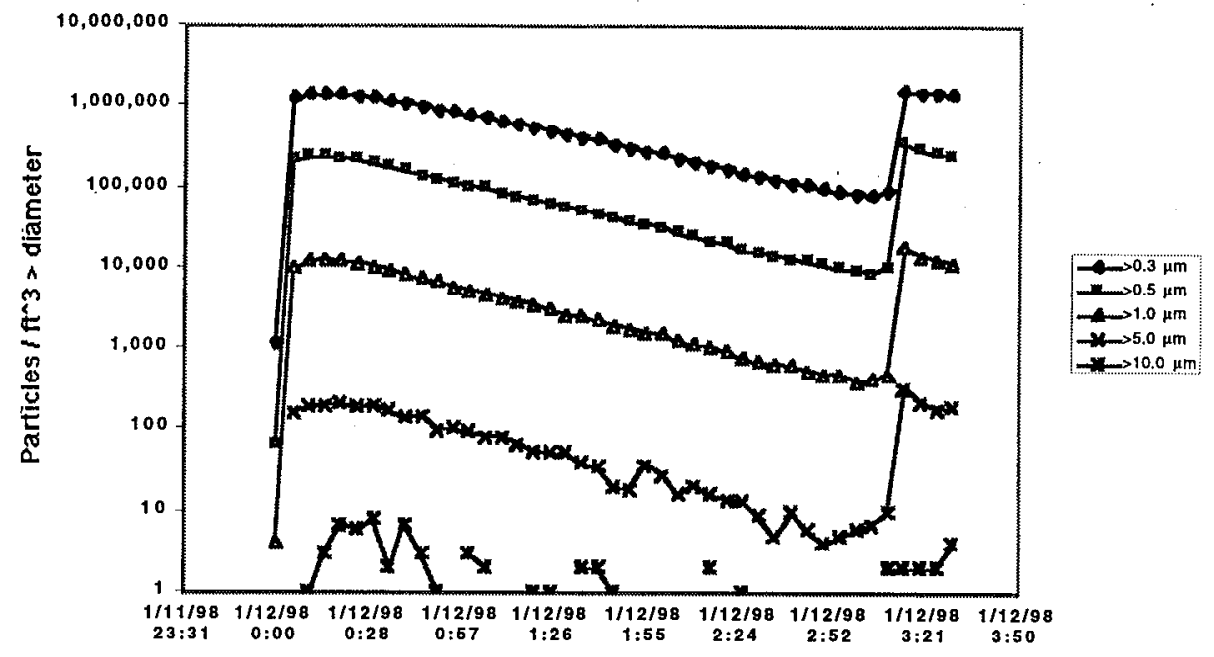

Figure 4: Aerosol measurement taken on the Beamlet laser at LLNL following two flashlamp firings. The concentration corresponds to a Class 200,000 aerosol that repcatcdly occurs after each flashlamp firing and dissipates at the rate of $1.5 \% / \mathrm{min}$. The dissipation rate approximately corresponds to the nitrogen replenishment rate divided by the system volume. A nitrogen replenishment rate is needed to maintain the system at a slightly positive internal pressure $\left(0.1\right.$ inch of $\left.\mathrm{H}_{2} \mathrm{O}\right)$ despite small system leaks.

Table 3: Laser induced mobilization thresholds in $\mathrm{mJ} / \mathrm{cm}^{2}$ and ultimate mobilization efficiencies (in parenthesis) for various surfaces and contaminants measured using 6-ns $1.064-\mu \mathrm{m}$ laser pulse light. Glasson-glass experimental results represent a lower-limit estimate and are currently being investigated.

\begin{tabular}{|r|c|c|c|c|c|}
\hline $\begin{array}{r}\text { Contaminant } \\
\text { vs. substrate surface }\end{array}$ & Glass Beads & Glass Shards & Nickel & Stainless Steel & $\begin{array}{c}\text { Arizona Road } \\
\text { Dust }\end{array}$ \\
\hline 5052 Aluminum & $48(30 \%)$ & No Stick & $312(25 \%)$ & 262 & 280 \\
\hline 304 Stainless Steel & $32(95 \%)$ & $32(45 \%)$ & $32(40 \%)$ & No Stick & 221 \\
\hline $\begin{array}{r}\text { Borosilicate Glass } \\
\text { Front Exposure }\end{array}$ & $>196$ & $>193$ & $72(70 \%)$ & $76(90 \%)$ & $72(50 \%)$ \\
\hline $\begin{array}{r}\text { Borosilicate Glass } \\
\text { Back Exposure }\end{array}$ & $>190$ & $>194$ & $10(90 \%)$ & $36(75 \%)$ & $10(50 \%)$ \\
\hline
\end{tabular}

In most of the cases studied, particle mobilization occurs at laser light levels commensurate with the scattered laser light levels (about 50-100 $\mathrm{mJ} / \mathrm{cm}^{2}$ ) present in the Nova and Beamlet laser systems and which are expected to be present in NIF. This suggests that laser assisted mobilization of contaminants in larger systems such as Nova, Beamlet, and NIF could play a significant role in establishing the contamination equilibrium observed along with vibration and laser induced degradation mechanisms already discussed. The experimental evidence shows that on transparent substrate surfaces (borosilicate glass), opaque contaminants are mobilized at lower laser fluences than transparent contaminants. The reverse scenario is also apparent where transparent contaminants are more easily mobilized than opaque species present on opaque metal surfaces. Additionally, laser exposure of the contaminants through the transparent media, called back-exposure, occurs at lower laser fluences when compared to laser exposure on the same surface side as the contaminants. Experience and experimental observations on Nova and Beamlet give evidence that slab cleanliness and damage is dependent upon which side laser exposure occurs. Backlit slab surfaces are cleaner than front-lit surfaces; however, more severe damage occurs on black-lit slab surfaces once established. Several explanations for particle mobilization on these surfaces can be rationalized to explain the data. First, particlc 
mobilization may result from the overcoming of Van der Waal's forces between the contaminants and the surfaces by supplying sufficient thermal energy to cause a large short-term acceleration from material thermal expansion. This can apply to the substrate surface, the contaminant material, or both species present. Second, the mobilization could result from actual destruction of thin substrate surface layers. The degradation provides stimuli in the form of plasmas and/or ejecta that could induce sympathetic contaminant removal via simple collision.

\section{DAMAGE TO LASER SLABS DUE TO EXTERNALLY APPLIED CONTAMINANTS}

The exact cause of slab damage has remained unanswered for a significant period of time primarily because of the nature of the damage. When previous slab amplifiers (Beamlet, NOVA, Novette, Shiva, Argus, etc.) were examined for damage, the preponderance of damage appeared as small fractures $(<1 \mathrm{~mm})$ on the disk surface with much of the central portion of the damaged area missing ${ }^{12}$. To understand this phenomenon, a series of phosphate and borosilicate glass samples were prepared with a low surface concentration of particulate contaminants. Table 4 lists the contaminants used for these experiments and which are similar to those found inside slab amplifiers. The contaminants represent species that are similar to those found inside slab amplifiers and cleanroom areas. The contaminants were applied to the surface of carefully cleaned 1-inch coupons of both common borosilicate and LG-770 phosphate laser glass. The contaminated coupons were then exposed to a bank of flashlamps with a flucnce of $10 \mathrm{~J} / \mathrm{cm}^{2}$ at the lamp surface.

Table 4: Each of these solid materials (and naturally occurring particulate materials) was subdivided into particles in a size range from $0.5-\mu \mathrm{m}$ to $1 \mathrm{~mm}$ and placed onto 1-inch square coupons of phosphate LG-770 and borosilicate glass. The loaded coupons were then exposed to an array of flashlamps with an output of $10 \mathrm{~J} / \mathrm{cm}^{2}$ at the lamp surface.

\begin{tabular}{|c|}
\hline Amplifier construction materials: Kapton, Polyethylene, Voranol \\
\hline $\begin{array}{c}\text { Typical cleanroom contaminants: Cleanroom garment fibers, } \\
\text { Cleanroom wipers, Lens tissue, Skin flakes }\end{array}$ \\
\hline $\begin{array}{c}\text { Contaminants found in amplifiers: Carbon black, Plexiglas, } \\
\text { Sherwin-Williams Polane paint, Teflon }\end{array}$ \\
\hline Cleanliness test standards: Arizona Road Dust (silicates) \\
\hline
\end{tabular}

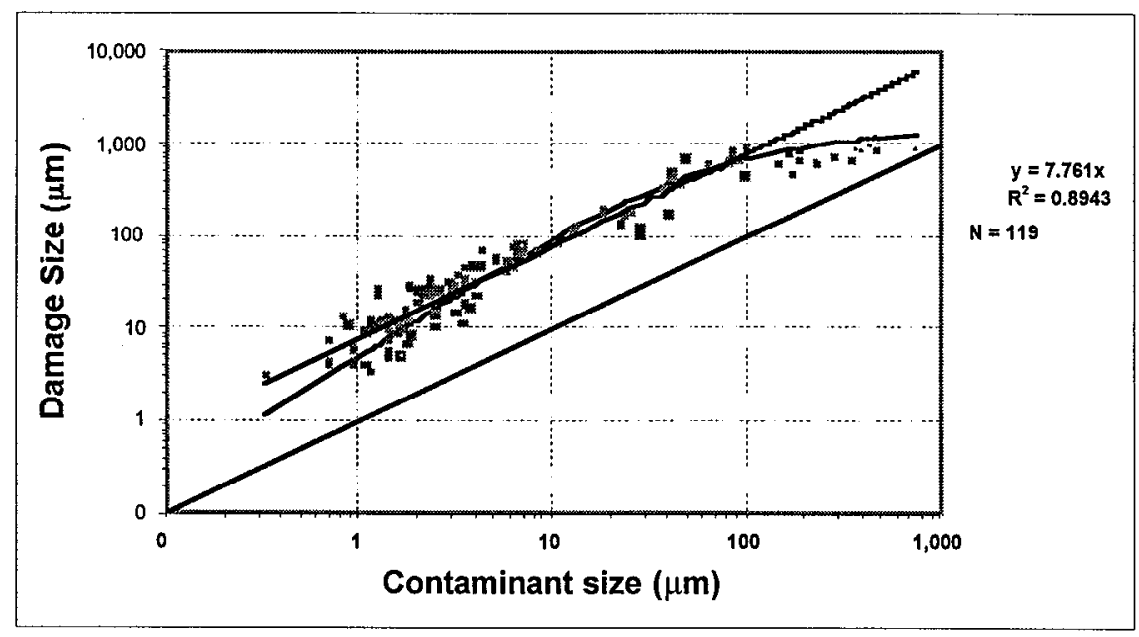

Figure 5: Initial contaminant size versus final flashlamp induced damage size. Contaminants placed onto phosphate (LG-770) and borosilicate glass were exposed to $1-3$ shots from a flashlamp array with an output of $10 \mathrm{~J} / \mathrm{cm}^{2}$ at the flashlamp surface. The ratio of damage size to initial contaminant size is consistent over the entire range of materials tested and wide size range of the contaminants. The flashlampinduced damage was found to be 7.8 times larger than the contaminant size that caused the damage.

The resulting damage was photographed using a dark-field microscope. The experiments conclusively demonstrale that every contaminant listed in Table 4 caused cracking of the glass surface within 1 to 3 flashlamp shots. The average size of the crazing damage is plotted as a function of the size of the contaminants and is shown in Figure 5. The flashlamp-induced damage was consistently found to be 7.8 times larger than the contaminant size that induced the damage. The appearance of a typical glass surface after flashlamp exposure tests is shown in Figures 6\&7. The general morphology of all of the 
contaminants was similar - a central or near central contaminant particle or area of high density cracking. Surrounding this is an area containing cracks characteristically seen in dry riverbeds. These areas contain thin sheets of cracked glass with a characteristic size of 30-50- $\mu \mathrm{m}$.

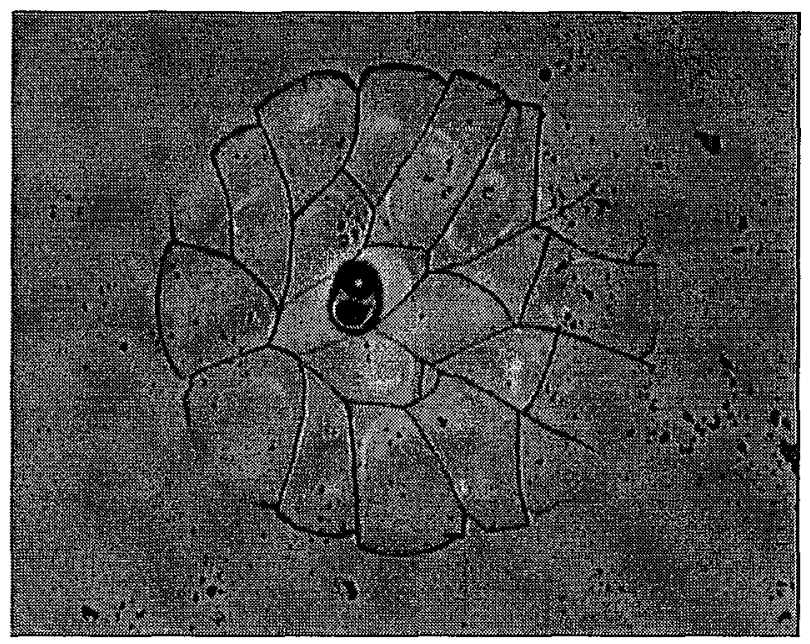

Figure 6: Damage to a borosilicate glass surface resulting from contamination with Arizona Road Dust followed by exposure to a single flashlamp pulse. A remnant of the contaminant that initiated the damage is clearly visible and the overall damage site is about 10 times larger than the contaminant particle that initiated the damage.

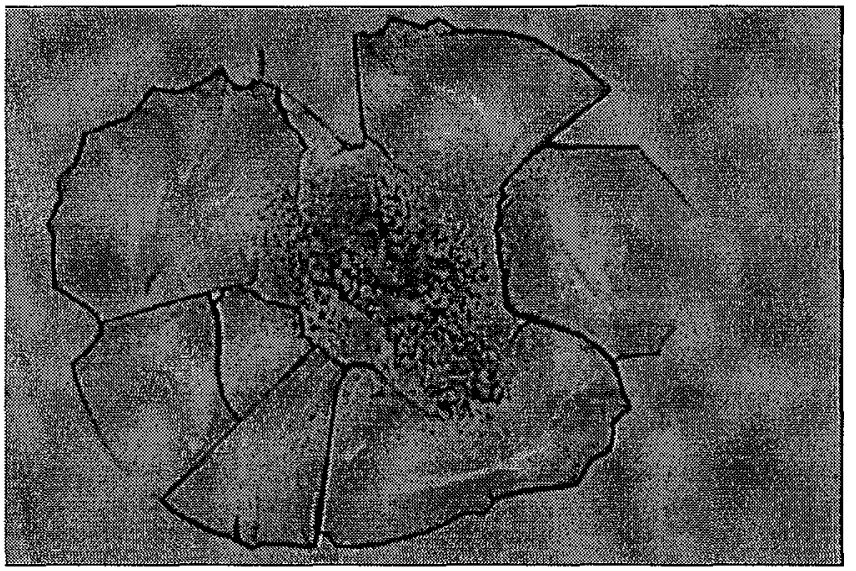

Figure 7: Damage to an LG-770 phosphate laser glass surface after contamination with a human skin flake and then exposed to a single flashlamp shot. The glass fractures into shallow petals with a characteristic size of $40-\mu \mathrm{m}$.

\subsection{Thermal gradient induced cracking}

The cause of the surface cracking or crazing is a local thermal gradient induced when flashlamp (or laser light) is absorbed by opaque or semi-opaque contaminants on slab surfaces. The temperature rise due to the $10 \mathrm{~J} / \mathrm{cm}^{2}$ flashlamp illumination can easily melt most metallic or oxide particles below $20-\mu \mathrm{m}$ in diameter. Organic materials typically pyrolyze (decompose) rather than melt. Their remnant materials, such as carbon tar, become increasingly more opaque with subsequent shots and ultimately result in surface crazing. Under these circumstances, it is vitally important to prevent even micron-sized particles of incompatible opaque materials and organic materials from reaching the surface of laser slabs, as they will induce local thermal gradients sufficient to crack the surface.

\subsection{Thermal shock parameter}

An analytic model describing the glass crazing phenomenon is generally referred to as the Thermal Shock Parameter $\left(R_{l}\right)$. Several authors agree that the ability of glass to resist thermal induced stresses is related to the glasses thermal expansion 
coefficient $(\alpha)$, Poisson's ratio $(v)$, thermal conductivity ( $\kappa)$, elastic modulus or Young's modulus $(E)$, tensile strength ( $\left.S_{1}\right)$, initial crack length (a), and fracture toughness $\left(\mathrm{K}_{\mathrm{lc}}\right)$. The thermal shock parameter $\left(\mathrm{R}_{t}\right)$ is given by either of the following formulas and typical values for common glasses are tabulated in Table 5. Note that because of LG-770's extremely high thermal expansion coefficient, it is particularly sensitive to surface crazing when compared to glasses such as Zerodur, ULE or fused quartz. The coefficient of thermal expansion of LG-770 is for example, 24 times larger than that of fused quartz.

$$
\begin{aligned}
& R_{t}=(1-v) \times\left(\frac{\kappa}{\alpha}\right) \times \frac{K_{1 c}}{E \sqrt{a}} \\
& R_{t}=(1-v) \times\left(\frac{\kappa}{\alpha}\right) \times\left(\frac{S_{t}}{E}\right)
\end{aligned}
$$

Table 5: Thermal shock parameter values for a variety of optical glasses. Due to their unusually high thermal expansion cocfficients, most solid-state laser glasses fall to the bottom of this list and are extremely sensitive to temperature gradients, which are easily generated when flashlamp absorbing contaminant particles inadvertently fall onto laser glass surfaces.

\begin{tabular}{|l|c|}
\hline \multicolumn{1}{|c|}{ Glass Type } & $\begin{array}{c}\text { Thermal Shock } \\
\text { Parameter, W/m }\end{array}$ \\
\hline Zerodur - silicate & 10,678 \\
\hline ULE (Code 7971) - silicate & 8,109 \\
\hline SiO $_{2}$ - fused quartz & 1,946 \\
\hline ED-2S - silicate & 538 \\
\hline LHG-5S - phosphate & 195 \\
\hline ED-2 - silicate & 123 \\
\hline LHG-5 - phosphate & 92 \\
\hline LG-750 - phosphate & 46 \\
\hline LG-770 - phosphate & 64 \\
\hline LHG-8 - phosphate & 68 \\
\hline
\end{tabular}

\section{SLAB DAMAGE DENSITY}

Surface cleanliness Levels and aerosol concentrations are typically measured and compared with the NIF cleanliness requirements to preclude the possibility of damage to laser slabs. In reality, however, slab damage levels need to be measured and compared to cleanliness Levels and aerosol concentrations to determine how these parameters are interrelated. The following information on slab damage levels is only tentative at this time because many slabs from the NOVA and Beamlet lasers have never been examined and their surface damage history quantified. This preliminary work, to collect damage maps for a variety of laser systems, will be significantly augmented when the Beamlet laser is decommissioned in July of 1998 and the NOVA laser decommissioned sometime in 1999.

\subsection{Damage density of Novette and NOVA slabs}

The Novette laser was constructed at LLNL to demonstrate the technical feasibility of constructing the much larger 10-beam NOVA laser. In 1984 after approximately 700 shots, the Novette laser was decommissioned and the amplifier disks used for its short lifetime were mapped to record damage history and considered for reuse on NOVA. Figure 8 shows the average size distribution of damage on five sizes of amplifier disks. The data has been separated into disk size groups because different size disks were oriented differently within the laser chain due to beam polarization considerations. For example, the 46-cm and $31.5-\mathrm{cm}$ disk amplifiers on Novette and NOVA were mounted with the disk normal vector parallel to the earth (the disks sit on edge). This is the orientation that has historically been observed to result in the lowest disk damage, presumably due to the settling of aerosols created within the amplifier. The $20.8-\mathrm{cm}$ disk amplifiers have the disks rotated $45^{\circ}$ away from the on-edge configuration. This configuration has been observed to be the worst configuration for the settling of aerosols and subsequent flashlamp induced damage. The density of damage on these Novette disks is between $20-80$ damage sites $/ \mathrm{ft}^{2} \geq 250-\mu \mathrm{m}$ size. Figure 8 also shows the damage size distribution for the six disk surfaces of a single $20.8-\mathrm{cm}$ amplifier after approximately 10,000 flashlamp firings. The three upward facing surfaces sustained between 40 to 150 damage sites $/ \mathrm{ft}^{2} \geq 250-\mu \mathrm{m}$ size whereas the downward facing surfaces sustained only 5 to 8 damage sites $/ \mathrm{ft}^{2} \geq 250-\mu \mathrm{m}$ size. 


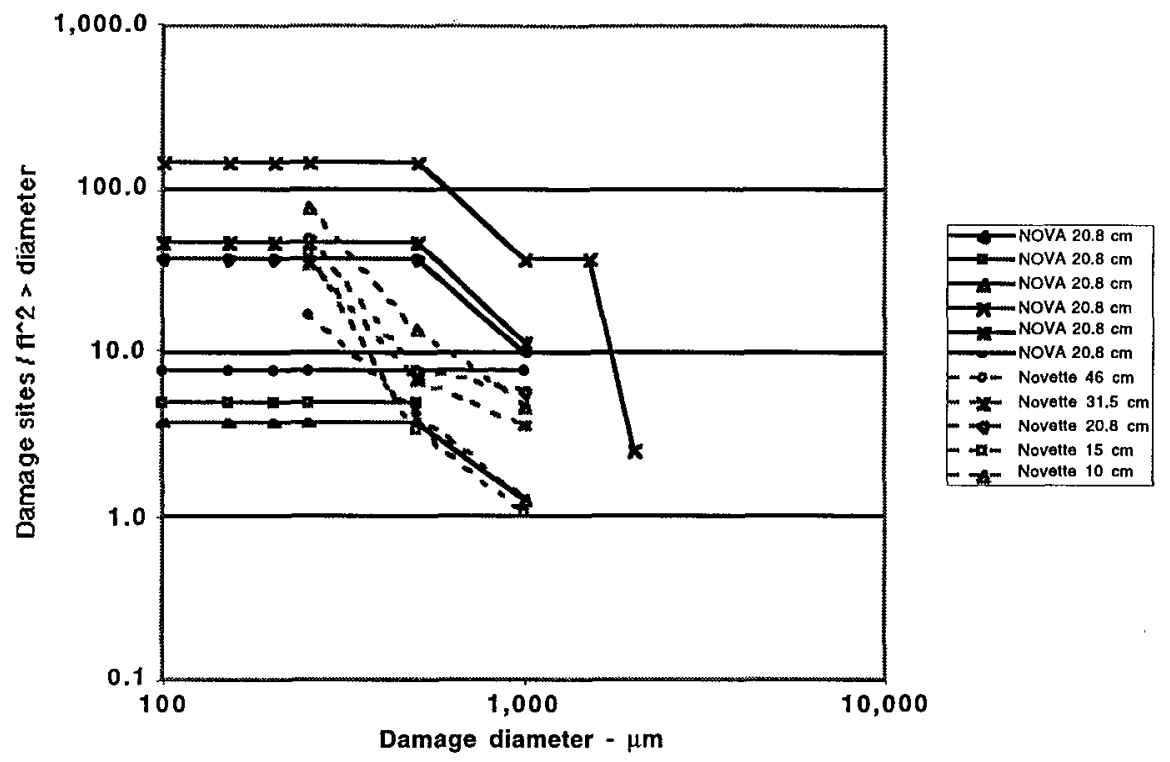

Figure 8: Examples of laser disk damage from the Novette and NOVA laser systems. At the $\geq 250-\mu \mathrm{ml}$ size, the damage concentration is about 20 sites/ $/ \mathrm{ft}^{2}$ for Novette $46-\mathrm{cm}$ amplifiers and approximately 80 sites/ $/ \mathrm{ft}^{2}$ for Novette 10-cm amplifiers. Damagc on all six surfaces of a NOVA 20.8-cm amplificr clcarly shows that upward facing surfaces sustain approximately 16 times more damage than downward facing surfaces.

\subsection{Damage density of Beamlet and AMPLAB slabs}

The Bcamlet laser is the predccessor to the NIF laser and is fitted with $400-\mathrm{mm} \times 700-\mathrm{mm}$ laser slabs mounted in the on-edge configuration. Figure 9 shows slab damage data taken from several amplifiers examined early in the Beamlet lifetime after only a few hundred flashlamp shots. The slab damage is very low and at the $\geq 250-\mu \mathrm{m}$ size indicates only about $2-4$ sites $/ \mathrm{ft}^{2}$ although there are still several damage sites in the 1-mm size range.

Figure 9 also shows the damage to a few $400-\mathrm{mm}$ by $700-\mathrm{mm}$ slabs tested in AMPLAB. Their damage density is in the range of 1-4 sites/ $\mathrm{ft}^{2} \geq 250-\mu \mathrm{m}$ diameter. In general, the observed damage to AMPLAB slabs is nearly identical to the Beamlet damage and a full order of magnitude lower than the damage level on NOVA and Novette shown in Figure 8.

\section{CONCLUSIONS}

The AMPLAB is a prototype NIF-like amplifier test facility constructed to evaluate the optical, thermal and cleanliness characteristics of the 400-mm x 700-mm slab amplifiers for NIF. The AMPLAB facility was designed to be assembled and operated in a Class 100 cleanroom so as to successfully demonstrate clean low-damage operations while undergoing inevitable changes associated with prototype hardware. Initial particulate cleanliness exceeded the NIF requirements of $\leq$ Level 100 structural surfaces, however, after several months of operation it was recleaned in-place and reached its goal of Level 100 cleanliness.

Further optical testing lead to observable slab damage and the system will again be disassembled, recleaned, and reassembled so as to demonstrate a long 500 flashlamp shot sequence during which slab damage will be closcly monitorcd.

During initial testing, it was observed that a Class 100,000 aerosol was created inside the amplifier after every flashlamp shot. Efforts to displace the aerosol by utilizing high velocity filtered nitrogen after each shot did not permanently remove the aerosol. Permanent removal might be expected if the aerosol represented post-cleaning debris that was simply being lifted off of surfaces and mixed into the nitrogen atmosphere after each shot. Chenical analysis showed the aerosol to be composed almost entirely of carbon and it was concluded that gaskets and other organic materials used in the construction of the amplifier were being pyrolyzed (decomposed) by the flashlamp light and thereby regenerating the aerosol after every shot.

It has also been shown experimentally that scattered laser light can displace contaminants from structural surfaces and result in the creation of aerosols leading to a cleanliness equilibrium within an amplifier cavity. The laser fluence (at 1.053- $\mu \mathrm{m}$ ) necessary to cause $50 \%$ of the initial contaminants to be displaced from surfaces is about $100-200 \mathrm{~mJ} / \mathrm{cm}^{2}$. This is also the 
laser fluence that is sufficient to cause plasma formation on surfaces and the formation of the plasma may in fact be the mechanism that drives small particles from the surface. This phenomenon is referred to as laser cleaning.

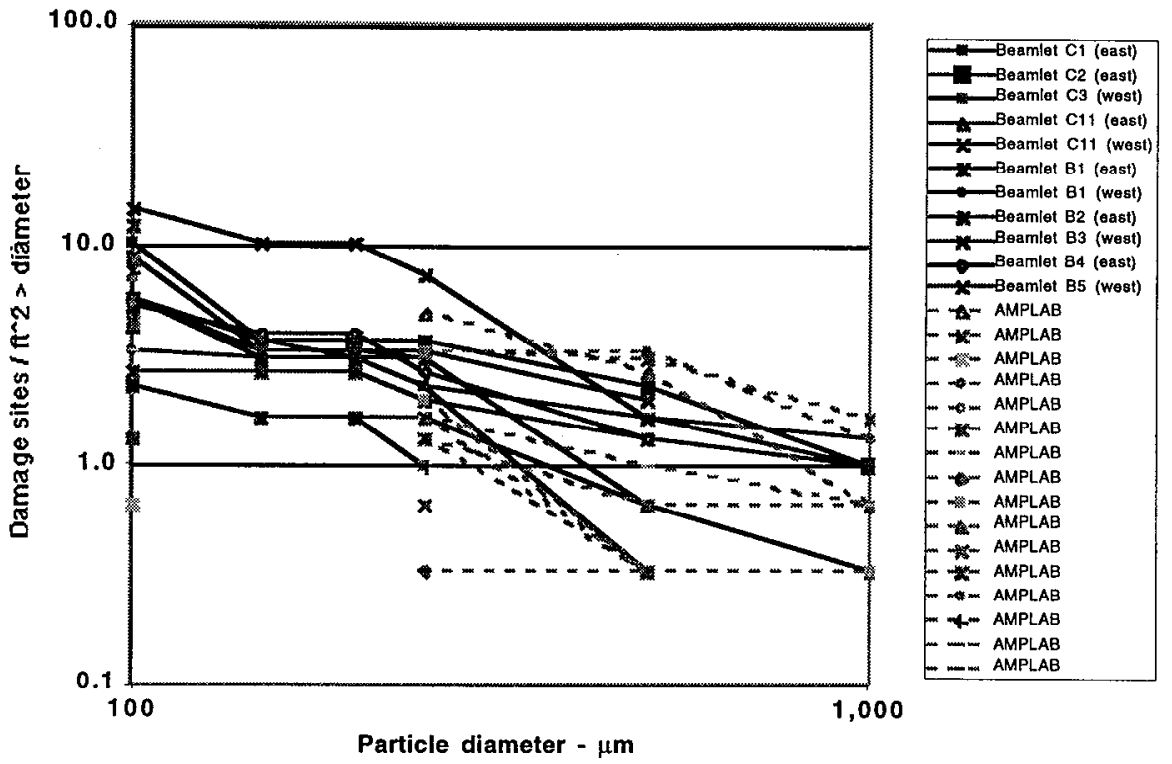

Figure 9: Laser disk damage from several Beamlet and AMPI.AB slabs. Damage is nearly identical on both systems despite Beamlet being in operation for 4 years.

Purposeful contamination of LG-770 with a large variety of contaminants followed by exposure to flashlamp fluence similar to that experienced inside of the NIF amplifiers conclusively showed that every contaminant that absorbs the flashlamp light will heat and result in a sufficiently high thermal gradient on the glass to cause the slab to crack or craze. The size of the crazing is $7.8 \mathrm{x}$ larger than the contaminant that caused the damage and therefore all contaminants greater than $5-\mu \mathrm{m}$ should be eliminated with special emphasis given to removing particles greater than $30-\mu \mathrm{m}$ in size. This size contaminant will result in a damage spot of $250-\mu \mathrm{m}$ diameter, which is the largest size damage acceptable on NIF. In general, this observation indicates that flashlamp driven damage is more severe than previously reported laser damage and therefore dominates the cleanliness requirements.

Surface cleanliness measurements on the Beamlet laser indicates that it has degraded in its cleanliness Level from better than Level 100 to Level 150-170. There is also ample evidence that the optics are as contaminated as the structural surfaces due to an aerosol transport process that drives all surfaces toward a cleanliness equilibrium. This is an undesirable condition because the cleanest surfaces will, over a period of time, acquire sufficient contaminants to reach the same cleanliness Level as neighboring surfaces.

A survey of Novette, NOVA, Beamlet, and AMPLAB slab damage densities indicates that edge mounted slabs always sustain less damage than upward facing disks or slab. The damage levels sustained by previous solid-state laser systems has decreased somewhat over the past 15 years with Beamlet having the lowest average damage levels. Furthermore, the NIF requirement of a single $250-\mu \mathrm{m}$ damage spot per disk surface will be difficult to achieve based on historical precedence. A dedicated test to demonstrate this very low level of slab damage is now underway in AMPLAB. This dedicated AMPLAB test should also determine if ultra-clean amplifiers can be constructed aerosol-free and if the lack of an aerosol is correlated with the lack of slab damage.

\section{ACKNOWLEDGMENTS}

The authors wish to thank the following individuals (in alphabetical order) for their significant contribution to the technical content of this paper and through whose help this work would not have been completed: Cindy Alviso, Prof. Ahmed Busnaina, Wilburt Davis, Gary Edwards, Susan Frieders, Prof. Costas Grigoropoulos, Dongsik Kim, Andrew Levin, Richard McCracken, Chuck Petty, and Douglas Ravizza.

Work performed under the auspices of the U.S. Department of Energy by Lawrence Livermore National Laboratory under Contract No. W-7405-Eng-48 


\section{REFERENCES}

${ }^{1}$ E. English, J. Downie, "Optical specifications for discrete material and surface defects and surface roughness based on loss analysis," Lawrence Livermore National Laboratory, NIF-96-434, May 9, 1996.

${ }^{2}$ Hunt, Manes, Renard, "Hot images from obscurations", Applied Optics, 32(30), Oct 1993.

${ }^{3}$ C. Widmayer, D. Milam, deSzoeke, "Nonlinear formation of holographic images of obscurations in laser beams", Applied Optics, 36(36), Dec 1997.

${ }^{4}$ Clay Widmayer and Paul A. Renard, "Survey of damage threat to vacuum barriers by defects and inclusions in NIF optical components", NIF-0008158, March 15, 1998, Lawrence Livermore National Laboratory, Livermore, CA.

5 "Military Standard 1246C-Product Cleanliness Levels and Contamination Control Program", Revised 1994 by the Institute of Environmental Sciences and Technology (IEST).

${ }^{6} \mathrm{~A}$ series of standardized gross and precision cleaning procedures have been established as follows; "MEL98-001 Fabrication and Handling of NIF I aser Components and Structures", "MEL 98-002 Cleaning of Cast Aluminum Alloy Components for NIF", "MEL98-003 Cleaning of Wrought Aluminum Alloy Components for NIF", "MEL98-004 Cleaning of 300 \& 400 Series CRES Steel Components for NIF", "MEL98-005 Cleaning of Copper and Copper Alloy Components for NIF", "MEL98-006 High Temperature Bake-out to Remove Volatile Organics for NIF", "MEL98-007 Precision $\mathrm{CO}_{2}$ Snow Cleaning for NIF Components", "MEL98-008 Precision High-Pressure Water Wash for NIF Components", "MEL98-009 Precision Ultrasonic Cleaning for NIF Components", "MEL98-010 Precision Surface Wiping for NIF Components", "MEL98-011 Gross High-Pressure Water Wash for NIF Components", "MEL98-012-Surface Cleanliness Validation by Swiping for NIF Components", "MEL98-013 Precision Ultrasonic Cleaning in OAB for NIF", "MEL98-014 Handling of Components for NIF and Guidelines for Creating and Maintaining Clean Area", "MEL98-015 Non-Volatile Residue Validation for NIF Components, Lawrence Livermore National Laboratory, Livermore, CA, June 1998.

7 "MEL98-012-Surface Cleanliness Validation by Swiping for NIF Components", Lawrence Livermore National Laboratory, June 1998.

${ }^{8}$ Tam, A.C., Leung, W.P., Zapka, W., Ziemlick, W., "Laser-Cleaning Techniques for Removal of Surface Particulates", Journal of Applied Physics B, Vol. 71, pp. 3515-3523, 1992.

${ }^{9}$ Climet Versaport 10, Climet Instrument Co, Redlands, CA.

${ }^{10}$ E. Grebot, O. Bonville, "Measurement of the Number of Particles in - The Cassette Flash Space", Feb 7, 1996, private communication.

${ }^{11}$ California Measurements, Inc., Model MPS-4G1.

${ }^{12}$ I. F. Stowers, H. G. Patton, "Damage History of Argus, a 4 TW Nd-Glass System", Symposium on Optical Materials for High Power Lasers, Boulder, CO, 4 Oct 1977. (UCRL-80419). 